\title{
A necessidade do impossível: pensar, ensinar, ler... a filosofia de uma escola popular
}

\section{La necesidad de lo imposible: pensar, enseñar, leer... la fillosofía de una escuela popular}

https://doi.org/10.34112/2317-0972a2016v34n67p13-25

Walter OMAR KOHAN ${ }^{1}$

RESUMO: A partir da necessidade de uma educação para o pensar, o presente texto apresenta Simón Rodríguez, autor venezuelano do século XIX, muito significativo na história das ideias pedagógicas latino-americanas. $\mathrm{O}$ texto justifica e contextualiza o pensar de Rodríguez, que afirma que o pensar deve estar entre as primeiras preocupações das práticas educacionais como se, nos primeiros passos, fosse o pensamento o eixo de todo ensinamento, muito mais ainda que o ler e escrever. Finalmente, ele conclui que fazer do pensar o sentido primeiro da vida educacional seja hoje um dos paradoxos mais imperativos para poder continuar a pensar que nós, os que habitamos estas terras latino-americanas, podemos viver uma outra vida e uma outra sociedade que a presente.

Palavras-chave: Educação para o pensar; Simón Rodríguez; cidadania.

RESUMEN: A partir de la necesidad de una educación para pensar, el presente texto presenta a Simón Rodríguez, un autor venezolano del siglo XIX, muy significativo en la historia de las ideas pedagógicas latino-americanas. El texto justifica y contextualiza el pensamiento de Rodríguez, quien afirma que el pensar debe estar entre las primeras preocupaciones de las prácticas educativas, como si, en los primeros pasos, fuese el pensamiento el eje de toda enseñanza, mucho más que el leer y escribir. Finalmente, concluye que hacer del pensar el

1. Universidade do Estado do Rio de Janeiro, Rio de Janeiro, RJ, Brasil. 
sentido primero de la vida educacional es hoy unos de las paradojas más imperativas para poder seguir pensando que los que habitamos esta tierra latino-americana podemos vivir otra vida y otra sociedad que la presente.

Palabras claVe: Educación para pensar; Simón Rodríguez; ciudadanía.

\section{ApresentaÇÃo: A Filosofia e A EdUCAÇÃo do PENSAR}

Na esteira de uma filosofia educacional pragmatista, a ideia de uma "educação para o pensar" como elemento principal das instituições educacionais foi desenvolvida, de um modo paradigmático, na última parte do século $\mathrm{XX}$, pelo filósofo norte-americano Matthew Lipman, criador e impulsor da proposta conhecida como "filosofia para crianças" (fpc; em inglês, philosophy for children). Lipman propôs não apenas uma fundamentação teórica, mas também um programa para implementação prática de uma "educação para o pensar", praticada atualmente com maior ou menor sucesso e alcance em mais de quarenta países dos cinco continentes ${ }^{2}$. $\mathrm{Na}$ introdução à segunda edição em inglês de sua obra teórica mais sólida, Thinking in Education (LIPMAN, 2003, p. 1-6), o autor deixa bem claro o propósito mais importante de sua tentativa: ${ }^{3}$ fazer do fortalecimento do pensar a principal tarefa da escola (LIPMAN, 2003, p. 1). Lipman oferece quatro formas de argumentar a favor dessa perspectiva: a) numa democracia, é fundamental que a escola forme seus futuros cidadãos para que sejam razoáveis e isso só pode ser conseguido cultivando o raciocínio e a capacidade de julgar dos estudantes; b) numa educação que cultiva o pensamento, os sistemas sociais tornam-se mais racionais, portanto, as escolas devem cultivar a racionalidade das crianças para que possam se inserir melhor nesses sistemas; c) requer-se ensinar as crianças a pensar não apenas pela sua utilidade mas também porque elas têm o direito de não receber menos do que isso (LIPMAN, 2003, p. 1-2).

2. Para um detalhamento de diferentes experiências pode se consultar a página do International Council of Philosophical Inquiry with Children (ICPIC): http://www.icpic.org ou o capítulo correspondente do relatório da UNESCO sobre a filosofia nos diversos níveis de ensino: UNESCO. Philosophy. A school of Freedom. Paris: UNESCO, 2011.

3. A edição desse livro de Lipman publicada no Brasil (Pensar na educação. Petrópolis, RJ: Vozes, 2005) está feita com base na tradução da sua primeira edição em inglês (Cambridge: Cambridge University Press, 1991). Lipman esclarece na introdução à segunda edição que as partes III e IV do livro, que perfazem mais da metade do mesmo, foram inteiramente reescritas. Infelizmente não há tradução ao português da segunda edição em inglês. 
Lipman não apenas enuncia a necessidade de uma educação para o pensar como afirma também algumas proposições complementares a levar em consideração: a) a filosofia é a disciplina capacitada para trazer uma melhora do pensar na educação; b) a comunidade de indagação é a pedagogia mais adequada para ensinar a pensar criticamente; c) não é por acaso que o pensamento crítico está associado a termos como "crítica" e "critério", que têm a ver com raciocinar, avaliar e julgar e neles deve se basear a "educação do pensar"; d) é preciso integrar outras dimensões do pensar (a criativa e a do cuidado) para educar numa concepção mais ampla do pensar (LIPMAN, 2003, p. 3-6).

Em outros textos, temos examinado criticamente a proposta de Lipman (KOHAN, 2002; 2013; 2014) e não pretendemos fazer isso aqui novamente. Contudo, queremos apresentar um outro autor, significativo na história das ideias pedagógicas latino-americanas, que pode nos ajudar a encontrar elementos mais próximos das nossas escolas e de nossa realidade cultural, social e política para fundamentar, de alguma forma, a partir de outros princípios e com outros sentidos, o pensar como eixo fundamental da educação.

\section{A escola POPUlar: Simón Rodríguez}

Esse autor é Simón Rodríguez, um dos principais defensores de uma educação popular filosófica no século XIX. No Brasil, Simón Rodríguez tem sido muito pouco lido e estudado. ${ }^{4}$ Nascido em Caracas em 1769, Rodríguez foi nomeado professor das primeiras letras pelo Cabildo de sua cidade com apenas 21 anos. Desempenha esse trabalho por alguns anos, quando tem entre seus alunos Simón Bolívar, até sair para um largo périplo pelas Américas Central e do Norte, e durante mais tempo pela Europa, onde reencontra Bolívar. Realizam uma série de viagens pedagógicas juntos e, em Roma, no Monte Sacro, Bolívar enuncia perante o seu mestre a sua promessa de não descansar até libertar o continente americano ${ }^{5}$ do domínio espanhol. Depois, Bolívar vai à América para cumprir sua promessa e Rodríguez continua no velho continente até esperar um momento mais propício para voltar, quando Bolívar já libertou alguns países e está em plena campanha militar. De acordo com as distintas biografias de Rodríguez (LASTARRIA, 1885; AMUNÁTEGUI, 1876; LOZANO

4. Apenas recentemente foi publicada a primeira edição de algumas das suas obras em português: Inventamos ou erramos (Belo Horizonte, MG: Autêntica, 2016).

5. Bolívar e Rodríguez usam América para se referir a América do Sul. Neste texto, manteremos esse sentido. 
Y LOZANO, 1913; ROJAS, 1979), o mestre teria viajado pela Alemanha, Áustria, Polônia, Rússia e Inglaterra entre 1806 e 1823, sempre trabalhando como professor, até retornar à América para completar, nos planos cultural e educativo, a libertação iniciada por Bolívar. Ficará mais de trinta anos viajando pela América Andina até sua morte no Peru em 1854 .

Em 1825, reencontra-se com Bolívar que o nomeia Diretor de Ensino Público de Ciências Físicas, Matemáticas e de Artes, uma espécie de Ministro de Educação da atual Bolívia. Nesse contexto, abre uma escola popular na cidade de Chuquisaca, que instaura uma novidade absoluta perante a realidade educativa da época (cf. DURÁN, 2016). A escola é inusitada, por exemplo, pelo fato de ser bilíngue, pois se aprendem nela as línguas quéchua e castelhana, e também por colocar na mesma sala meninas e meninos. Porém, o caráter mais revolucionário da escola encontra-se no fato de que o "Colégio de Órfãos e Meninos Carpinteiros" se caracteriza por receber a todos os meninos e meninas da cidade em qualidade de iguais. Diferentemente do resto das escolas americanas, que recebiam seus alunos de acordo com sua origem social, econômica e étnica, a escola de Rodríguez aceitava todos como iguais, sem condições. ${ }^{6}$ De acordo com sua perspectiva, a escola popular é para todos, porque todos são cidadãos e iguais (RODRÍGUEZ, 2001a, I, p. 284).

Uma vez partido Bolívar, o convívio de $S$. Rodríguez com outros aliados de Bolívar, como o General Sucre, não é fácil.? Decididos a manter as hierarquias sociais, econômicas e políticas da ordem colonial, eles dispersam uma série de rumores maliciosos sobre a pessoa e o trabalho de Rodríguez, que renuncia ao seu cargo e dá início a novas viagens pela Bolívia, Chile, Equador e Peru, onde morre em 1854. Sempre viaja acompanhado por dois baús onde guarda seus escritos, comunica sua ideia de uma escola para todos, trabalhando sempre como professor, vivendo sempre em condições precárias. Eventualmente consegue publicar seus trabalhos, sem muito sucesso.

6. O mundo escolar americano dos primeiros anos do século XIX encontra-se caracterizado por uma educação hierárquica e diferenciada. Em todo o continente, existem diversos tipos de instituições educativas que recebem os distintos grupos sociais e étnicos estruturados a partir das reformas dos Bourbons. Para mais detalhes, ver García Sánchez (2005) e Escobari de Querejazu (2009).

7. Para uma perspectiva mais precisa do caraquenho sobre a situação com essas figuras, pode-se ler com proveito a correspondência de Rodríguez com Bolívar e outros personagens da época em RODRÍGUEZ, $2001 b$. 
EDUCAÇão POPULAR, FILOSOFIA E POLÍtTiCA

Quase todas as obras de Rodríguez fazem referência à questão educacional. Para o caraquenho, só através da educação era possível introduzir as transformações que a América necessita para tornar-se uma república. Eis, por exemplo, o início de um dos seus principais textos, Luzes e Virtudes Sociais, publicado em Valparaíso em 1840, que constitui um verdadeiro manifesto de uma educação popular:

\author{
O objeto do autor, tratando das Sociedades \\ americanas, é a \\ EDUCAÇÃO POPULAR
}

$$
\begin{aligned}
& \text { e por } \\
& \text { POPULAR.... entende.... GERAL }
\end{aligned}
$$

\title{
INSTRUIR não é EDUCAR
}

\section{Nem a Instrução pode ser equivalente à Educação}

\section{Ainda que Instruindo se Eduque}

Como prova de que ao acumular conhecimentos, diferentes da arte de viver, nada se tem feito para formar a conduta social - veem-se os muitos sábios mal educados, que povoam o país das ciências. Um filólogo pode falar de estratégia com propriedade e não ser, por isso, soldado.

Tampouco são meios de GENERALIZAR

nem podem suprir

os contínuos atos de PUBLICAÇÃO que se fazem

ensinando em Escolas, Colégios e Universidades, nem os de DIVULGAÇÃO

que se fazem pela imprensa

o que não é geral

sem exceção

não é verdadeiramente PÚBLICO

e

o que não é PÚBLICO não é SOCIAL.

(RODRÍGUEZ, 2016, p. 73, destaques do autor) 
Destacamos alguns elementos desse texto: uma educação popular é uma educação geral, de todxs, sem exceções, sem ninguém de fora das instituições educacionais; claro que não se trata simplesmente de escolarizar ou instruir, de repassar conhecimentos, senão de uma verdadeira educação que concilie teoria e prática, que ensine as pessoas não apenas saberes teóricos, mas a arte de viver. Por último, o caraquenho nos deixa um legado político de enorme importância para os dias de hoje: uma educação para todos, geral, social só pode ser uma educação pública. Vimos também como em Sociedades americanas, em 1828, afirma: "escola para todos porque todos são cidadãos” (RODRÍGUEZ, 2001a, I, p. 284), ou seja, não é na escola que se constrói a cidadania, mas é porque os que entram na escola são cidadãos que nela se forma num modo de vida republicano. Não se entra na escola para ser cidadão: é porque se é cidadão que se entra na escola.

Nesse sentido, Simón Rodríguez, embora concorde com Lipman sobre a importância da filosofia na educação (e ele é muito claro nesse sentido: "a instrução pública no século XIX pede MUITA FILOSOFIA” - RODRÍGUEZ, 2016, p. 79), ele também propõe uma inversão dos argumentos a favor de uma educação baseada no pensamento, como os sustentados por Matthew Lipman. Não é a escola ou um ensino pautado pela filosofia que faz de alguém um cidadão: a cidadania é prévia, constitutiva dos que precisam entrar na escola, não para se tornarem cidadãos, o que já são, mas sim para que aprendam a viver essa cidadania de um certo modo, no caso, republicano. Eis ali e só ali que o pensar tem um papel fundamental para os que já são cidadãos e por isso estão na escola, na medida em que o pensar que se aprende na escola está a serviço de uma vida mais republicana, e a escola é uma escola popular, ou seja, para todxs.

Sobre o papel e a incumbência da filosofia, Simón Rodríguez afirma:

A filosofia está onde quer que se pense sem prevenção; e consiste em conhecer as coisas, para regrar nossa conduta com elas, segundo sua propriedades. Os preceitos sociais são poucos, e suas aplicações... muitas: pretender que se ensine o pouco que se deve saber para não errar nos muitos casos que ocorrem a cada dia... é filosofia: - esperar que, se todos sabem suas obrigações e conhecem o interesse que possuem em cumpri-las, todos viverão de acordo, porque se atuará por princípios... não é sonho nem delírio, mas filosofia...; nem o lugar onde isso se faça será imaginário, como o que imaginou o Chanceler Thomas Morus: sua utopia será, na realidade, a América. (RODRÍGUEZ, 2016, p. 93-94, destaques do autor). 
Ou seja, a filosofia seria algo assim como um conhecimento dos primeiros e poucos princípios elementares para uma vida republicana. Pensar sem prever; apenas viver segundo esses princípios. E se a filosofia fosse de verdade para todxs, se todxs vivessem na filosofia, então a América, como Rodríguez chama ao continente do Sul, seria a realização da utopia. Uma filosofia verdadeira, engajada com o pensamento e a vida de toda a sociedade. Filosofia social e política portanto, e também filosofia popular, ao alcance da vida de todxs xs habitantes destas terras.

\section{A PRIORIDADE DO PENSAR SOBRE LER}

Assim, Simón Rodríguez se situa na mesma esteira de Lipman a respeito da importância de uma educação baseada no pensamento. Esse princípio atravessa seus escritos. Contudo, o pensador da educação popular é ainda mais incisivo do que Lipman ao afirmar que o pensar deve estar entre as primeiras preocupações das práticas educacionais como se, nos primeiros passos, fosse o pensamento o eixo de todo ensinamento, muito mais ainda que o ler e escrever. Não que Lipman desconsidere essa possibilidade; de fato, ele tem começado propondo a filosofia nos últimos anos do ensino fundamental e estendido sua aplicabilidade a todo o currículo escolar. E tem argumentado a favor da possibilidade da filosofia nos primeiros anos, muito mais do que da sua necessidade, como faz Rodríguez em diversas obras, mais incipientemente nas primeiras e mais enfaticamente nas últimas. Por exemplo, já no seu primeiro texto publicado, de 1794, o caraquenho faz uma crítica aguda de como se desvaloriza e subestima a formação dos encarregados da primeira educação das crianças. Trata-se, nada mais e nada menos, do que a educação através das primeiras ideias das coisas:

Para que uma criança aprenda a ler e escrever, mandam-na à casa de qualquer vizinho, sem mais exame que o saber que quer ensiná-la, porque se supõe habilidade; e gozam de grande satisfação as mães quando veem que o professor veste hábitos, porque em seu conceito é o traje símbolo da Sabedoria. Ah! De que modo tão distinto pensariam se examinassem qual é a obrigação de um Professor de Primeiras Letras, e o cuidado e delicadeza que devem observar em dar ao homem as primeiras ideias de uma coisa. (RODRÍGUEZ, 2016, p. 40, destaque nosso). 
Essa mesma ideia perpassa suas obras, intensificando-se a cada vez. Em um trecho de Luzes e virtudes sociais, em que faz referência ao Projeto Constitucional de Simón Bolívar que deixaria fora da cidadania aqueles que, depois de determinado prazo, não soubessem ler e escrever, comenta, com marcada ironia:

Com respeito à língua, lê-la é tão necessário como falá-la com pureza; mas o que irá ler quem não entende os livros? do que falará quem não tem ideias? Não será necessário ir muito longe para buscar um exemplo que responda essa pergunta. $O$ tratado sobre as luzes e sobre as virtudes sociais em quantas mãos cairá que se dignem a abri-lo?... Visto o título, quantos o terminarão?... quantos entenderão bem o que terão lido?... quantos partidários terá tido a Instrução Geral?... quantos a protegerão ativamente?... e quem a colocará em prática? Prática?!...?!...?!

IDEIAS!... IDEIAS!, primeiro que LETRAS. (RODRÍGUEZ, 2016, p. 93, destaques do autor).

No seu estilo, na sua língua, ensaiando uma escrita singular e original, Simón Rodríguez é muito claro e dialoga com os discursos contemporâneos do letramento: há, sim, que se ensinar a ler e escrever, claro, mas antes de nada, há que se ensinar a pensar, para poder compreender o sentido do que se lê e escreve. A prioridade do pensar é substantiva, originária... não se trata apenas de uma questão cronológica; o "antes" é um início vindo da necessidade de os estudantes se situarem de forma crítica e criativa em relação às letras... Não se trata apenas de ler e escrever mas, sobretudo, de sua transposição prática, ou seja, da medida em que as letras permitem a todxs xs habitantes destas terras viver uma vida mais humana. E para isso, é preciso, antes de mais nada, ideais sobre como habitar uma sociedade melhor para todxs xs que a integram.

Em seu último texto, "Conselhos de amigo, dados ao Colégio de Latacunga" (1850-1), publicado um século depois de sua morte, Rodríguez (2016, p. 215) faz uma apologia à primeira escola, à "escola social", à sua importância para formar os habitantes originais de que a América precisa. Nesse contexto, insere sua crítica ao método lancasteriano, que alfabetiza mecanicamente, que faz da arte de ensinar uma técnica e da aprendizagem reflexiva uma repetição memorística, própria mais de papagaios do que de cidadãos da república (RODRÍGUEZ, 2016, p. 218). A consequência é a formação de cidadãos dóceis e reprodutores de uma ordem já estabelecida, exatamente o contrário do que se precisa nestas terras. 
Trata-se, portanto, do pensar como uma arte e não como uma técnica, de escrever como se pinta, de ler como se esculpe. Nesse sentido, em Extracto sucinto de mi obra sobre Educación Republicana, de 1849, Rodríguez critica duramente o ensino instrumental de lógica formal ou do silogismo aristotélico, que acaba sendo utilizado para defender argumentos reprováveis do ponto de vista ético e político, sem sequer considerar seu conteúdo ou suas consequências. Por exemplo, nas escolas monárquicas, parte-se de premissas tais como a) esse índio não é o que eu sou, e b) eu sou homem; para concluir, delas, que o índio é bruto e que, portanto, deve ser colocado para trabalhar aos golpes. (RODRÍGUEZ, 2001a, I, p. 243).

Eis um chamado da atenção para os que, em nosso tempo, têm feito da "educação para o pensar" um ensino de habilidades e competências. Pensar não é simplesmente dominar e conseguir pôr em prática habilidades, técnicas, ferramentas de pensamento. Pensar não é uma técnica; ao contrário, é ser sensível às necessidades de todxs xs que habitam uma terra. Quem, através do seu pensamento, legitima uma ordem colonial opressora, o faz num sentido derivado e insubstancial do verbo pensar.

Nessa mesma obra, Rodríguez dedica uma seção especial à "Primeira Escola". Ali, Rodríguez reafirma, sem deixar dúvidas, a prioridade do pensar sobre o ler: "LERé o último ato no trabalho do ensino. A ordem deve ser... Calcular-Pensar-Falar-Escrever e Ler. Não... ler-escrever e contar, e deixar a lógica (como se faz em todas partes) que a sorte leva até os Colégios" (RODRÍGUEZ, 2001a, I, p. 243). Repare-se, no início, o que muitas vezes se considera abstrato demais para uma criança, como calcular ou pensar e, depois, o que se supõe mais concreto, como escrever o ler. Há várias razões para isso: a confiança que Rodríguez tem na capacidade de todxs xs seres humanos; sua aposta na necessidade de uma aprendizagem reflexiva da leitura e da escrita; sua crença no impacto da primeira escola em todas as outras instâncias da cadeia educativa e na própria vida das pessoas; os impactos e valores sociais e políticos que Rodríguez confere a um ensino reflexivo numa sociedade republicana. Poderíamos continuar com outros testemunhos, mas talvez seja já momento de oferecer nossa própria perspectiva sobre as questões aqui apresentadas.

\section{A filosofia e A NeCesSidade do impossível: ensinar a PENSAR}

No momento em que estou terminando de escrever o presente texto, consuma-se mais um momento trágico da história política do Brasil. Uma presidente legitimamente eleita pelo povo brasileiro é afastada de suas funções por um processo 
indecoroso e ilegítimo de golpe de estado encoberto sob o guarda-chuva do poder legislativo a partir da aliança de setores econômicos, judiciários e midiáticos. A ordem colonial insiste em perpetuar-se. A democracia treme no Brasil, e na América Latina inteira.

As relações entre filosofia, educação e política são complexas. Não há espaço para demarcações simplistas e simplificadoras. Contudo, algo parece evidente: os efeitos de uma educação tecnicista, instrumentalista, a-filosófica, são por demais evidentes. É também evidente que a filosofia não é uma mágica solução educacional para os problemas políticos de uma sociedade tão complexa quanto a brasileira. Mas não é menos evidente que a realidade política que hoje vive o país não pode ser separada de uma história educacional instrumentalmente colonizadora, quase uma prolongação daquela que Simón Rodríguez exigia abandonar como condição de uma vida verdadeiramente republicana, há quase duzentos anos.

Por fim, são também notórios os paradoxos da filosofia em sua relação com a política e a educação. Com respeito à primeira, pelo menos desde o Sócrates ateniense, sabemos que se, por um lado, quem pratica a filosofia é o único a fazer a política verdadeira (PLATÃO, Górgias 521d; 2006), por outro lado, ela opõe-se dramativamente à política e, assim, não tem espaço na pólis, como é manifesto na Apologia de Sócrates de Platão (2006); única política verdadeira, ela não apenas não pode ser praticada na pólis como é perseguida e condenada à morte. A política dos que administram a ordem na pólis não tolera a política da filosofia. Sócrates ateniense que o diga. A escrita e a vida do Sócrates de Caracas, S. Rodríguez, ${ }^{8}$ revivem esse confronto paradoxal: ele, o único verdadeiro político, o criador da escola igualitária e popular, apenas pôde praticar sua política sob o amparo de Bolívar e, quando este parte a continuar sua campanha militar, Rodríguez é expulso, acusado de louco, estrangeiro, delirante. Desta vez, a política da filosofia é recusada e mandada ao exílio pela política dos administradores do estado das coisas. ${ }^{9}$

No campo educacional, a situação da filosofia não é menos paradoxal. Também desde o Sócrates de Atenas sabemos desse paradoxo, pois Sócrates declara não ter sido mestre de ninguém (Platão, Apologia de Sócrates 33a, 2006) e, no entanto, que alguns têm aprendido com ele (ibid., 33b-c). A acusação da política contra a filosofia só faz sentido pelos efeitos educacionais da filosofia, mas Sócrates se encarrega de

8. Assim o chamava S. Bolívar (Cf. RODRÍGUEZ, 2001b, p. 117).

9. Vê-se, dentre outros testemunhos, a carta de S. Ródríguez a Bolívar (RODRÍGUEZ, 2001b, p. 141). 
mostrar que não pode ser acusado de ensinar quem nada sabe. Porém, sua defesa denota o paradoxo: o professor de filosofia não ensina, mas outros aprendem com ele. Ninguém aprende nada de Sócrates porque ele próprio nada sabe, a não ser que não sabe (Apologia 2od-24b), mas é justo esse não saber que revoluciona e refunda a relação pedagógica em um novo início. Sócrates, e com ele a filosofia, não ensina à maneira de um transmissor, mas na forma de um provocador. Simón Rodríguez continua a prática da filosofia como provocação da ordem instituída. Por exemplo, na sua escola popular quer colocar juntxs meninas e meninos. Como a sociedade colonial não tolerava que fossem educadxs num mesmo lugar pessoas de distintos gêneros, ele as junta em salas de aula contíguas e abre portas e janelas para pôr em comunicação as meninas e meninos. (RODRÍGUEZ, 2001a, II, p. 357).

Nessa mesma esteira, J. Derrida (1990) mostra como a disciplina filosófica desdobra-se numa série de antinomias na sua institucionalização ${ }^{10}$ : ela não pode ser dissociada de seu ensino mas, ao mesmo tempo, o gesto mais propriamente filosófico, o que permite alguém experimentar o pensar filosófico, nãa pode ser ensinado; com efeito, a filosofia ao mesmo tempo exige ser ensinada, mas o gesto filosófico mais essencial, o pensar filosófico enquanto tal só pode ser aprendido... ninguém pode, significativamente, filosofar sozinho, sem um outro e, a uma só vez, ninguém ensina ninguém a filosofar; em todo caso, aprende-se a filosofar com outro, mas não de outro... Assim, não se pode filosofar sem essa pretensão impossível de ensinar a filosofar...

Voltemos a Simón Rodríguez: é imprescindível ensinar a pensar nas escolas se quisermos ter uma vida social mais plena para todxs, sem ninguém fora. Como ensinar filosofia, ensinar a pensar é tão necessário como impossível. As considerações finais, não podem não ser paradoxais: a filosofia, como disciplina, está longe de poder ser uma solução mágica para as necessidades da educação brasileira. Mas sua ausência é também um sintoma da im-possibilidade de sua potência para uma transformação social e política urgente e necessária. Afinal, a filosofia, mais do que uma disciplina, é um modo de vida. Nisso, coincidem os dois Sócrates, Lipman e tantos outros. Para terminar, talvez seja ainda significativo ler S. Rodríguez:

Só com a esperança de conseguir que se pense na EDUCAÇÃO DO POVO pode-se advogar pela INSTRUÇÃO GERAL:... e deve-se advogar por ela; porque chegou o tempo

10. As antinomias enunciadas por J. Derrida são oito. Aquí só enunciamos as mais próximas ao nosso interesse. 
de ensinar as pessoas a viver, para que façam bem o que se faria mal sem que se pudesse remediar. Antes, deixavam-se governar, porque acreditavam que sua única missão, neste mundo, era obedecer: agora não [o] acreditam, e não se pode impedir que pretendam, nem (... o que é pior...) que ajudem a pretender. (RODRÍGUEZ, 2016, p. 74).

Chegou o tempo de ensinar as pessoas a viver. Ensinar a pensar é um caminho, ao mesmo tempo necessário e impossível, para ensinar a viver. A vida está cheia de paradoxos, a educação também. Talvez fazer do pensar o sentido primeiro da vida educacional seja hoje um dos paradoxos mais imperativos para poder continuar a pensar que nós, os que habitamos estas terras, podemos viver uma outra vida e uma outra sociedade que a presente.

\section{REFERÊNCIAS}

AMUNÁTEGUI, M. L. Ensayos biográficos. Santiago de Chile: Imprenta Nacional, 1876.

DERRIDA, J. Le droit a la philosophie, Paris : Galilée, 1990.

DURÁN, M. Simón Rodríguez. Una filosofía de la radical novedad. Caracas: Ediciones del Solar, 2016. ESCOBARI DE QUEREJAZU, L. Historia de la alfabetización en Bolivia: época colonia s XVIXVIII. Estudios Bolivianos, n. 15, 2009.

GARCÍA SÁNCHEZ, B. Y. La educación colonial en la Nueva Granada: entre lo doméstico y lo público. Revista de Historia de la Educación Latinoamericana, v. 7, 2005.

KOHAN, W. Philosophy \& Childhood: Critical Perspectives and Affirmative Practices. New York: Palgrave MacMillan, 2014. . O mestre inventor: relatos de um viajante educador. Belo Horizonte: Autêntica, 2013. . Lipman y la Filosofía. Notas para pensar un concepto. In: MORIYÓN, F. G. (org.). Matthew Lipman. Educación y Filosofía. Madrid: Ediciones de la Torre, 2002, p. 49-69.

LASTARRIA, J. V. Recuerdos literarios: datos para la historia literaria de la America española: del progreso intelectual en Chile. Santiago de Chile: Librería Servat, 1885.

LIPMAN, M. Thinking in Education. 2nd ed. Cambridge: Cambridge University Press, 2003. LOZANO Y LOZANO, F. El maestro del Libertador. París: Ollendorff, 1913. PLATÃO. Diálogos. Belém, PA: Universidade Federal de Pará, 2006.

RODRÍGUEZ, S. Obra Completa. Tomos I-II. Caracas: Presidencia de la República, $2001 a$. . Cartas. Caracas: Ediciones del Rectorado de la UNISER, $2001 \mathrm{~b}$. . Inventamos ou erramos. Belo Horizonte, MG: Autêntica, 2016.

ROJAS, A. Crónicas y leyendas. Caracas: Monte Ávila Editores Latinoamericana, 1979. 
OUTRAS OBRAS DE INTERESSE

ÁLVAREZ FREITES, M. Simón Rodríguez tal cual fue: vigencia perenne de su magisterio. Caracas: Ediciones del Cuatricentenario de Caracas, 1966.

CASTELLANOS, R. R. Simón Rodríguez, pensador universal y pulpero de Azángaro. Caracas: FOGADE, 2007.

GUEVARA, A. Espejo de justicia. Caracas: Ediciones del Consejo Rector de la Universidad Nacional Experimental Simón Rodríguez, 1954.

JORGE, C. Educación y revolución en Simón Rodríguez. Caracas: Monte Ávila Editores Latinoamericana, 2000.

LASHERAS, J. A. Simón Rodríguez: maestro ilustrado y político socialista. Caracas: Universidad Nacional Experimental Simón Rodríguez; Ediciones Rectorado, 2004.

PIETRI, U. La isla de Robinson. Caracas: Seix Barral, 1981.

RUMAZO GONZÁLEZ, A. Simón Rodríguez: maestro de América. Caracas: Universidad Simón Rodríguez, 1976.

\section{SOBRE O AUTOR}

Walter Omar Kohan é graduado em Filosofia (Universidade de Buenos Aires - Argentina), com Doutorado (Universidad Iberoamericana - México) e PósDoutorado (Université Paris 8 - Vincennes-Saint-Denis - França) na mesma área. É professor titular da Universidade do Estado do Rio de Janeiro e Pesquisador do Conselho Nacional de Desenvolvimento Científico e Tecnológico (CNPq) e do Prociência (UERJ/FAPERJ). Participa de Projetos de Pesquisa Interinstitucionais junto a Universidades Nacionais e Internacionais e coordena, desde 2007, o Projeto de Extensão em Escola Pública (“Em Caixas a Filosofia en-caixa?”, UERJ/ FAPERJ).É orientador de mestrado, doutorado e pós-doutorado nas áreas de ensino de filosofia, infância e filosofia da educação. Em suas atividades profissionais interagiu com mais de 50 colaboradores em co-autorias de trabalhos científicos. E-mail:wokohan@gmail.com

Recebido em 15 de maio de 2016 e aprovado em 20 de junho de 2016. 